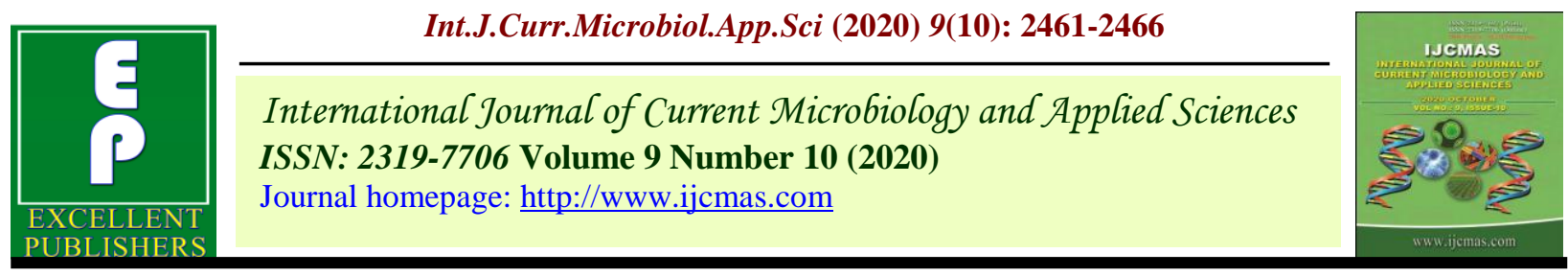

Original Research Article

https://doi.org/10.20546/ijcmas.2020.910.294

\title{
In vitro Appraisal of Botanicals and Bioagents against Alternaria brassicicola Inciting Alternaria Leaf Spot of Cabbage
}

\author{
Vidhi Chamoli ${ }^{1}$, S. Ravi ${ }^{1 *}$, S. K. Verma ${ }^{2}$ and A. K. Singh ${ }^{3}$ \\ ${ }^{1}$ Department of Plant Pathology, ${ }^{2}$ Department of Food Science \& Technology, ${ }^{3}$ Department \\ Vegetable Science, College of Horticulture, VCSG UUHF, Bharsar, (Pauri Garhwal) \\ Uttarakhand, India \\ *Corresponding author
}

\section{A B S T R A C T}

\begin{tabular}{|l|}
\hline Ke y w or d s \\
$\begin{array}{l}\text { Cabbage, Alternaria } \\
\text { brassicicola, } \\
\text { Botanicals, Neem, } \\
\text { Bioagents and } T \text {. } \\
\text { asperellum }\end{array}$ \\
\hline Article Info \\
\hline $\begin{array}{l}\text { Accepted: } \\
17 \text { September } 2020 \\
\text { Available Online: } \\
10 \text { October } 2020\end{array}$ \\
\hline
\end{tabular}

The efficacy of botanicals and bioagents against Alternaria leaf spot of cabbage is caused by Alternaria brassicicola. Among the botanicals tested, the maximum per cent mycelium growth inhibition was found in neem $(35.67,38.14,40.95,47.17$ and $57.64 \%)$ followed by garlic $(26.88,28.94$, $32.61,35.14$ and $41.83 \%$ ) and Tulsi, respectively. Whereas, minimum growth inhibition was found in camphor at (100, 500, 1000, 1500 and 2000 ppm). In bioagents, T. asperellum (73.55\%) was most effective followed by T. harzianum (67.22\%), P. fluorescens (64.45\%), whereas, B. cereus was least effective.

\section{Introduction}

Cabbage is most preferable crops among the consumers for Indian and continental cuisine. The production of cabbage is mostly affected by various biotic factors at different stages of plant. The Alternaria causes of the heavy yield losses of different vegetable family viz. cucurbitaceae, brassicaceae and solanaceous. The three major species of Alternaria that causes serious damage to brassicas: $A$. brassicicola, A. brassicae and A. raphani infect cabbage, cauliflower, kale, brussels sprouts, Chinese cabbage and turnip. There are two species of Alternaria which cause serious damage in cabbage: Alternaria brassicae and A. brassicicola, they can survive saprophytically outside of the host and diseased crop debris (Yadav et al., 2014). Alternaria black leaf spot is the most destructive disease of cabbage and brassicas worldwide (Meah et al., 2002). A complex of Alternaria species (A. brassicicola (Schw.) Wiltsh., A. brassicae (Berk.) Sacc., A. alternata (Fr.) Kreissler and A. raphani Groves and Skolko) are responsible for 
important yield losses (Verma and Saharan, 1994). Mycelium of necrotrophic fungus $A$. brassicicola is septate, olive grey to grayish black in colour. The conidiophores are olivaceous, septate, branched measuring 35$45 \mu \mathrm{m}$ in length and 5-8 $\mu \mathrm{m}$ in width. Conidia are dark, cylindrical to oblong, muriform without beak measuring 44-55 $\mu \mathrm{m}$ in length and 11-16 $\mu \mathrm{m}$ in width with 5-8 transverse and 0-4 transverse septa. The fungus grows faster in media with high sporulation and appears as well developed black sooty colour with distinct zonations (Kolte, 1985). Plants inoculated with $A$. brassicicola develop symptoms most quickly at $25^{\circ} \mathrm{C}$, while seedlings from infected seeds develop symptoms most quickly at $30^{\circ} \mathrm{C}$. No germination occurs at $3^{\circ} \mathrm{C}$ for all three pathogens namely $A$. brassicicola, $A$. brassicae and $A$. raphani (Bassey and Gabrielson, 1983). Among fungal diseases, Alternaria leaf spot of cabbage caused by $A$. brassicicola is seriously damage the production of cabbage around the world. Alternaria leaf spot is the most destructive diseases on cabbage. Mostly $20 \%$ of agricultural breakdown is caused by Alternaria spp. The major serious losses may reach upto $80 \%$ of yield and $59 \%$ loss of cabbage seed yield may causes due to Alternaria blight (Hossain and Mian, 2004). Alternaria leaf spot decreasing yield upto $50 \%$ without using any control (Cline, 2002). The present study was aimed for determining an effective management with botanicals and bio-agents on Alternaria leaf spot of cabbage.

\section{Materials and Methods}

\section{Evaluation of botanicals against $A$. brassicicola}

The experiment was conducted at Department of Plant Pathology, College of Horticulture, VCSG UUHF Bharsar (Pauri Garhwal) Uttarakhand, during 2018-19.The eight botanicals i.e. neem (Azadirachta indica), garlic (Allium sativum), nettle (Urtica dioica), lemongrass (Cymbopogon citratus), mint (Mentha piperita), vach (Acorus calamus), tulsi (Ocimum tenuiflorum) and camphor (Cinnamomum camphora) at 100, 500, 1000, 1500 and 2000 ppm.

\section{Preparation of botanicals}

Plant extracts were prepared by grinding the required quantity of leaves $(100 \mathrm{~g})$ before grinding equal quantity of water added in the respective plant leaves $(1: 1 \mathrm{w} / \mathrm{v})$. The crude extract of botanicals was filtered different leaves was sieved through double layered muslin cloth. Each of the filtrate obtained was further filtered through Whatman No.1 filter paper using funnel and volumetric flasks (100 $\mathrm{mL}$ cap.) The final clear extracts obtained formed the standard plant extracts of 100 per cent concentration and the extract thus obtained were kept in a refrigerator at $4 \pm 1^{\circ} \mathrm{C}$ by using poisoned food techniques (Nene and Thapliyal, 1993). The flasks were shaken gently to ensure the proper mixing of botanicals in PDA, $20 \mathrm{~mL}$ of molten and cooled PDA was poured in each Petri plate. After solidification of media, mycelial disc (5 $\mathrm{mm}$ ) were cut from the edges of seven days old culture of test pathogen with the help of sterilized cork borer. The fungus was incubated at $25 \pm 2{ }^{\circ} \mathrm{C}$ for five days with four times replicated. The observation on colony diameter in $(\mathrm{mm})$ was recorded and per cent inhibition over control, calculated by using formula given.

\section{Evaluation of bioagents against $A$. brassicicola}

Four bioagents i.e. Trichoderma harzianum, Trichoderma asperellum, Pseudomonas fluorescens and Bacillus cereus were evaluated for their antagonistic properties against $A$. brassicicola following dual culture 
technique (Faheem et al., 2010). The bioagents and the test fungus were inoculated both sides on a single Petri plates containing solidified PDA with four replications for each treatment. Control was also run along with the other treatments. Inoculated plates were incubated at $25 \pm 2{ }^{\circ} \mathrm{C}$ for five days. The radial growth of the colony of bioagents and the pathogen measured in two directions and average radial mycelia growth was recorded. Per cent mycelia growth inhibition was calculated by using the formula of Vincent (1947).

Per cent mycelia inhibition $=\frac{\mathrm{C}-\mathrm{T}}{\mathrm{C}} \times 100$

Where,

$\mathrm{C}=$ Colony mycelia in control

$\mathrm{T}=$ Colony mycelia in treatment

The data noticed was analyzed by using standard statistical procedure in the simple completely randomized design (CRD) with the help of OPSTAT and Graph Pad (3.05).

\section{Results and Discussion}

\section{Effect of botanicals on mycelial growth of A. brassicicola}

The observations were recorded in (Table 1) clearly indicates that all the test botanicals and bioagents were significantly superior over control on the growth of A. brassicicola. Among botanicals, the maximum per cent mycelium inhibition of $A$. brassicicola was recorded in neem $(35.67,38.14,40.95,47.17$ and $57.64 \%)$ followed by garlic $(26.88,28.94$, $32.61, \quad 35.14$ and $41.83 \%$ ), tulsi and lemongrass, whereas the minimum per cent mycelium inhibition of $A$. brassicicola was recorded in camphor followed by vach, nettle and mint, respectively. Raza et al., (2015) also observed the similar result, among all five tested plant extracts, Azadirachta indica was significantly superior over other treatments followed by Allium sativum, Parthenium hysterophorus and Datura stramonium. Least inhibition was observed in Eucalyptus camaldulensis (49.31\%). Overall results demonstrated that all the tested concentrations of Azadirachta indica were found significantly effective for controlling early blight of tomato. Gupta et al., (2019) also found that the neem plant extract was found highly effective against pathogen at both concentrations (15\% and $25 \%$ ) and mycelial inhibition was recorded $(65.55$ at $15 \%$ and 68.88 at $25 \%$ ). Sasode et al., (2012) found related result like among the crude extract 10 per cent the minimum fungus growth was recorded in neem followed by eucalyptus, tulsi, lantana, datura and pudina. Neem was significantly superior over tulsi, lantana, datura and pudina but at par with eucalyptus. Mesta et al., (2009) found that neem leaf extract with 38.49 per cent inhibition of spore germination and 43.90 per cent inhibition of mycelial growth was effective than all other plant extracts. Ravi et al., (2014) also tested different botanicals against $R$. solani inciting leaf blight of Kalmegh (Andrographis paniculata). Garlic extract at $15 \%$ was found to be most effective with $78.89 \%$ inhibition followed by thuja extract at $15.0 \%$ concentration with $75.56 \%$ inhibition. Vivekanand et al., (2018) found that neem extract at $600 \mathrm{ppm}$ resulted in maximum (57.20\%) mycelial growth inhibition followed by garlic extract $(53.83 \%)$ against $C$. capsici.

\section{Effect of bioagents on mycelial growth of} A. brassicicola

Evaluation of bio-agents per cent inhibition of mycelia over control against A. brassicicola in (Table 2) revealed that maximum per cent inhibition was recorded in Trichoderma asperellum (73.55\%) followed by $T$. 
harzianum (67.22\%), Pseudomonas fluorescens $(64.45 \%)$ whereas, Bacillus cereus was least effective. Kuzmanovska et al., (2018) reported that the both bioagents, antagonists inhibited the mycelial growth ( $T$. asperellum from $74.24 \%$ and $T$. harzianum from $71.07 \%$ ). These bio-control agents used for control of gray mold disease in tomato. Patil and Prajapati (2017) also found that the highest growth inhibition was recorded in $T$. asperellum (74.72 \%) followed by T. viride $(69.86 \%)$ and $T$. harzianum $(66.80 \%)$ to control the Rhizopus soft rot of tomato. Khalse et al., (2017) also observed that the maximum mycelial growth was recorded in $\mathrm{T}_{1^{-}} \quad$ Trichoderma harzianum (65.21\%) followed by $\mathrm{T}_{2}$ Pseudomonas fluorescens $(62.41 \%)$. Similar, findings were also reported by Chavan et al., (2015) and Maheshwari and Krishna (2013).

Table.1 Effect of botanicals on per cent mycelium inhibition of A. brassicicola

\begin{tabular}{|c|c|c|c|c|c|c|c|c|c|c|}
\hline \multirow[t]{3}{*}{ Treatments } & \multicolumn{10}{|c|}{ Average per cent mycelium growth inhibition } \\
\hline & \multicolumn{2}{|c|}{ 100ppm } & \multicolumn{2}{|c|}{ 500ppm } & \multicolumn{2}{|c|}{ 1000ppm } & \multicolumn{2}{|c|}{ 1500ppm } & \multicolumn{2}{|c|}{2000 ppm } \\
\hline & $\mathbf{G}$ & $\mathbf{I}$ & $\mathbf{G}$ & $\mathbf{I}$ & $\mathbf{G}$ & $\mathbf{I}$ & $\mathbf{G}$ & $\mathbf{I}$ & $\mathbf{G}$ & $\mathbf{I}$ \\
\hline Control & 67.10 & 0.00 & 67.10 & 0.00 & 67.10 & 0.00 & 67.10 & 0.00 & 67.10 & 0.00 \\
\hline Neem & 43.15 & 35.67 & 41.50 & 38.14 & 39.41 & 40.95 & 35.44 & 47.17 & 28.39 & 57.64 \\
\hline Garlic & 49.05 & 26.88 & 47.67 & 28.94 & 45.22 & 32.61 & 43.51 & 35.14 & 39.02 & 41.83 \\
\hline Nettle & 59.09 & 11.88 & 57.43 & 14.40 & 55.04 & 17.96 & 53.22 & 20.67 & 50.57 & 24.63 \\
\hline Lemongrass & 55.53 & 17.23 & 53.37 & 20.45 & 51.51 & 23.21 & 48.07 & 28.35 & 46.86 & 30.15 \\
\hline Mint & 57.52 & 14.27 & 55.87 & 16.72 & 53.92 & 19.64 & 51.97 & 22.53 & 48.72 & 27.38 \\
\hline Vach & 60.22 & 10.24 & 58.15 & 13.32 & 56.33 & 16.03 & 54.43 & 18.86 & 51.35 & 23.45 \\
\hline Tulsi & 53.61 & 20.09 & 51.42 & 23.35 & 49.17 & 26.71 & 47.28 & 29.52 & 43.44 & 35.24 \\
\hline Camphor & 61.06 & 8.98 & 59.47 & 11.36 & 57.55 & 14.21 & 55.34 & 18.26 & 53.39 & 20.75 \\
\hline S.E.(d) & 0.40 & - & 0.33 & - & 0.28 & - & 0.25 & - & 0.38 & - \\
\hline C.D.(0.05) & 0.83 & - & 0.68 & - & 0.59 & - & 0.52 & - & 0.78 & - \\
\hline
\end{tabular}

$\mathrm{G}=$ Average mycelia growth in $(\mathrm{mm}) ; \mathrm{I}=$ Average mycelia growth inhibition in (\%)

Table.2 Effect of bioagents on per cent mycelia growth inhibition of A. brassicicola

\begin{tabular}{|l|c|c|}
\hline Treatments & $\begin{array}{c}\text { Mycelial growth(mm) } \\
\text { SE(m) }\end{array}$ & Percent inhibition of mycelia growth \\
\hline Control & $67.10 \pm 0.04$ & 0.00 \\
\hline Trichoderma harzianum & $21.55 \pm 0.10$ & 67.22 \\
\hline Trichoderma asperellum & $17.39 \pm 0.20$ & 73.55 \\
\hline Bacillus cereus & $30.09 \pm 0.09$ & 54.25 \\
\hline Pseudomonas fluorescens & $23.38 \pm 0.14$ & 64.45 \\
\hline S.E.(d) & $\mathbf{0 . 1 8}$ & - \\
\hline C.D.(0.05) & $\mathbf{0 . 3 9}$ & - \\
\hline
\end{tabular}

In bioagents Bacillus cereus, Pseudomonas fluorescens and Trichoderma harzianum were tested for antagonistic properties against $A$. alternata under in vitro (Tekiner et al., 2019).
Raj Hans and Sharma (2017) found that among the bio-agents $T$. harzianum exhibited mycelial growth inhibition $(46.15 \%)$ to evaluate their inhibitory effects against the $A$. 
alternata causing mouldy core, core rot of apple. Ravi et al., (2014) also found that Trichoderma harzianum (Th-4) caused maximum $88.71 \%$ (in vitro) inhibition followed by $T h-12$ with $78.63 \%$ whereas, Pseudomonas fluorescens was least effective against $R$. solani. Vivekanand et al., (2018) found that in vitro assessment of bio-control agents i.e. T. harzianum was found more effective with $50.89 \%$ inhibition than $P$. fluorescens against C. capsici.

In conclusion the tested eight botanicals against $A$. brassicicola at five different concentrations $(100,500,1000,1500$ and $2000 \mathrm{ppm}$ ) in which maximum mycelium growth inhibition was obtained in neem followed garlic and Tulsi, respectively; while minimum inhibition was observed in camphor. Among four bioagents tested, maximum growth inhibition was found in $T$. asperellum, while Bacillus cereus was least effective.

\section{Acknowledgement}

The authors are highly grateful to Dean, College of Horticulture and OIC, MAP Block Bharsar (Pauri Garhwal) Uttarakhand for extending support.

\section{References}

Bassey, E.O. and Gabrielson, R.L. 1983. The effects of humidity, seed infection level, temperature and nutrient stress on cabbage seedling disease caused by Alternaria brassicicola. Seed Sci. Technol.11:403-410.

Chavan, P. G., Apet, K. T., Wagh, S. S. and Hingole, D. G. 2015. Efficacy of fungicides, botanicals and biogents against Alternaria brassicae of cauliflower. Trends in Biosciences. 8(8): 1920-1934.

Cline, W. O. 2002. Blueberry bud set and yield following the use of fungicides for leaf spot

control in North Carolina. Acta Hortic. 574.7.

Faheem, A., Razdan, V.K., Mohiddin, F.A., Bhat, K.A. and Sheikh, P.A. 2010. Effect of volatile metabolites of Trichoderma species against seven fungal plant pathogen in vitro. Journal of Phytopathology. 2:34-37.

Gupta, P., Chandra, R. and Dubey, P. 2019. Bio-efficacy of plants extract against Alternaria brassicicola causing Alternaria leaf spot of cabbage. Journal of Pharmacognosy and Phytochemistry. 8(1): 2332-2334.

Hossain, M. S. and Mian, I. H. 2004. Effect of foliar fungicides on the control of Alternaria blight of cabbage seed crop. Bangladesh Journal Plant Pathology. 20(1 and 2): 43-48.

Khalse, K. D., Lal, A. A. and Simon, S. 2017. Efficacy of bio-agents and plant extracts against the Alternaria leaf spot of cabbage (Alternaria brassicae). Journal of Pharmacognosy and Phytochemistry. 6(4): 1980-1982.

Kolte, S. J. 1985. Diseases of Annual Edible Oilseed Crops Vol. II. RapeseedMustard and Sesamum Diseases. CRC Press Boca Raton, Florida, USA: p.135.

Kuzmanovska, B., Rusevski, R., Jankuloski, M. and Oreshkovikj, K. B. 2018. Antagonistic activity of Trichoderma asperellum and Trichoderma harzianum against genetically diverse Botrytis cinerea isolates. Chilean Journal of Agricultural Research. 78(3): 391- 399.

Maheshwari, S. K. and Krishna, H. 2013. Field efficacy of fungicides and bioagents against Alternaria leaf spot of mung bean. Annals of Plant Protection Sciences. 21(2): 364-367.

Meah, M. B., Hau, B. and Siddique, M. K. 2002. Relationship between disease parameters of Alternaria blight (Alternaria brassicae) and yield of 
mustard. Journal of Plant Diseases and Protection 3: 243-251.

Mesta, R. K., Benagi, V. I. Srikant, K. and Shankergoud, I. 2009. In vitro evaluation of fungicides and plant extracts against Alternaria helianthi causing blight of sunflower. Karnataka Journal of Agricultural Science. 22:111113.

Nene, Y.L. and Thapliyal, P.N. 1993.Poisoned food technique, Fungicides in Plant Disease Control. 3rd Edn., Oxford \& IBH Publishing Company Pvt. Ltd, New Delhi, last reprinted 2015. pp. 531.

Patil, R. K. and Prajapati, B. K. 2017. Effect of Trichoderma spp. and its culture filtrate antagonists on growth and management of Rhizopus rot of tomato fruit in vitro and in vivo. Journal of Pharmacognosy and Phytochemistry. 6(4): 394-398.

Raj Hans and Sharma, J. N. 2017. In vitro evaluation of botanicals, bio-agents and fungicides against Alternaria alternata causing mouldy core, core rot of apple. International Journal of Agriculture Sciences. 9(49): 4835-4840.

Ravi, S., Vishwanath., Kumar, S. and Kumar, P. 2014. Evaluation of botanicals, cow urine and biocontrol agents against Rhizoctonia solani inciting leaf blight of Kalmegh (Andrographis paniculata). Plant Disease Research. 29(1): 46-49.

Raza, W., Ghazanfar, M.U., Iftikhar, Y.,
Ahmed, K.S., Haider, N., Rasheed, M.H. 2016 Management of early blight of tomato through the use of plant extracts. Int. J. Zool. Stud:1(5):1-4.

Sasode, R. S., Prakash, S., Gupta, A., Pandya, R.K. and Yadav, A. 2012. In vitro study of some plant extracts against Alternaria brassicae and Alternaria brassicicola. Journal of Phytology. 4(1): 44-46.

Tekiner, N., Kotan, R., Tozlu, E. and Dadasoglu, F. 2019. Determination of some biological control agents against Alternaria fruit rot in quince. Alinteri Journal of Agriculture Sciences. 34(1): 25-31.

Verma, P. R. and Saharan, G. S. 1994. Monograph on Alternaria diseases of crucifer. Minister of Supply and Services, Saskatoon,Canada.

Vincent, J. M. 1947.Distrotion of fungal hyphae in the presence of certain inhibitors. Nature. 159:239-241.

Vivekanand., Ravi, S., Mishra, R. C. and Nautiyal, B. P. 2018. Evaluation of fungicides, botanicals and biocontrol agents against chilli anthracnose caused by Colletotrichum capsici. Plant Disease Research. 33(1): 64-68.

Yadav, C.L., Kumar, N., Kumar, R. 2014. Effect of Seed Treatments with Fungicides Bio-agents and Botanicals against Alternaria Leaf Spot in Cabbage (Brassica oleracea var. capitata L.). Trends in Biosciences. 7(23): 38233827.

\section{How to cite this article:}

Vidhi Chamoli, S. Ravi, S. K. Verma and Singh, A. K. 2020. In vitro Appraisal of Botanicals and Bioagents against Alternaria brassicicola Inciting Alternaria Leaf Spot of Cabbage. Int.J.Curr.Microbiol.App.Sci. 9(10): 2461-2466. doi: https://doi.org/10.20546/ijcmas.2020.910.294 